\title{
Predictors of Adherence to Treatment in Women With Fibromyalgia
}

\author{
Patricia L. Dobkin, PhD,* Aurelio Sita, PhD, $\dagger$ and Maida J. Sewitch, PhD*
}

\begin{abstract}
Objectives: The goal of this study was to identify predictors of general and medication adherence in women with fibromyalgia (FM).

Methods: Participants were 142 women recruited from tertiary care hospitals or the community and 10 rheumatologists. Participants' demographic, clinical, and psychosocial characteristics, as well as patient-physician discordance, were assessed at the index visit. Adherence was assessed 6 months later. Multivariable generalized estimating equations were used to identify predictors of general adherence and adherence to medication.
\end{abstract}

Results: The average age of participants was 50.9 years $(\mathrm{SD}=10.2)$ and the median duration of FM was 32 months. Participants reported extensive use of health services and medications. The mean score for general adherence was 61.0 $(\mathrm{SD}=22.4$; range $0-100)$ and $52.9 \%$ of the cohort reported at least one form of behavior reflecting nonadherence to medications. More general adherence was significantly predicted by lower patient-physician discordance on patient well-being and lower patient psychological distress. Medication adherence was significantly predicted by higher affective pain and lower patient psychological distress.

Conclusions: Adherence is influenced by both clinical (patientphysician discordance and pain) and psychological (distress) factors in women with FM. Improvements in these domains may improve adherence in FM.

Key Words: fibromyalgia, predictors, adherence, compliance, patient-physician discordance

(Clin J Pain 2006;22:286-294)

$\mathrm{F}$ bromyalgia (FM), although classified as a syndrome in rheumatology, ${ }^{1}$ is also considered a chronic pain condition. ${ }^{2,3}$ Prevalence is estimated at $2 \%$ to $3 \%$ of adults in the Western world. ${ }^{4}$ It predominantly affects

Received for publication April 20, 2004; first revision August 23, 2004; second revision February 27, 2005; accepted May 23, 2005.

From the *Department of Medicine, McGill University, Montreal, Quebec, Canada; and $†$ Division of Clinical Epidemiology, McGill University Health Centre, Montreal, Quebec, Canada.

Supported by Arthritis Society of Canada Grant \#410-96-0516.

Reprints: Dr. Patricia L. Dobkin, McGill University Health Centre, Division of Clinical Epidemiology, L10 417, 1650 Ave. Cedar, Montreal, Quebec, Canada H3G 1A4 (e-mail: patricia.dobkin@ mcgill.ca).

Copyright (C) 2006 by Lippincott Williams \& Wilkins middle-aged women. Patients report widespread body pain and nonrestorative sleep/fatigue and often present with comorbid conditions such as headaches, irritable bowel syndrome (IBS), and other arthritic diseases. FM patients use conventional and complementary health services extensively and consume a wide array of medications. ${ }^{5}$ Little is known, however, about the extent to which patients follow health professionals' recommendations.

Close examination of studies involving FM patients receiving different interventions (medications, exercise, cognitive-behavior therapy) reveals that "attrition" from treatment, ${ }^{6}$ rather than adherence per se, is documented in some studies. ${ }^{7}$ Even when a detailed description of multidisciplinary group programs ${ }^{8}$ is provided, there is no mention of either direct assessment of adherence or its relation to clinical outcomes. One exception is found in Huyser et $\mathrm{al}^{9}$; these authors compared 87 FM patients' adherence during three different programs (exercise, biofeedback, and exercise plus biofeedback). Significant group differences were found, with the biofeedback group showing the best adherence. Although adherence was considered to be high across the groups, it was measured as a dichotomous variable for only 6 weeks. With regard to adherence to medications, Sewitch et $\mathrm{al}^{10}$ noted that about half of the women with FM were nonadherent to medications 2 weeks after being examined by a rheumatologist. Of these, $33.3 \%$ were intentionally nonadherent, $40.0 \%$ were unintentionally nonadherent, and the remaining women were both. Overall nonadherence with medications was predicted by higher patient-physician discordance on communication and satisfaction. Discordance may be especially important in FM because many physicians do not consider FM to be a "real" disease, and so patients are often dissatisfied with the medical encounter. ${ }^{11}$ The physician-patient alliance may affect adherence ${ }^{12}$ and thereby contribute indirectly to outcomes.

There are several challenges inherent in studying adherence in this clinical population. First, patients with FM use conventional and complementary services concurrently and extensively. FM patients' treatments are often provided by different health professionals and are rarely integrated into one coherent program (at least in Quebec, Canada; this may differ elsewhere). Second, they consume numerous medications that may be prescribed by different physicians and use various over-the-counter remedies. Third, FM patients typically have other medical 
conditions. It is, therefore, difficult to determine which health recommendations have been given for what disorder. In some cases, advice may generalize across conditions (eg, stress management for FM and IBS).

Although adherence in FM has rarely been studied directly, chronic pain patients' adherence to multidisciplinary interventions has been examined. ${ }^{13}$ Turk and Rudy $^{13}$ noted that noncompliance (the term formerly used in medical settings) with treatment regimens was widespread across diverse treatment modalities and pain syndromes. The literature was inconsistent with regard to which patient characteristics (eg, personality type) were related to adherence. Nonetheless, somatization, ${ }^{14}$ perceived disability, ${ }^{14,15}$ and pain intensity ${ }^{14,16,17}$ have been related to early withdrawal from multidisciplinary pain programs. In Davis and Addis' 1999 review $^{18}$ of predictors of attrition from behavioral medicine treatments for chronic pain populations, organic diagnosis, number of dropouts for a particular therapist, positive feedback from others regarding the patient's pain, and the credibility of the program were found to predict attrition.

In the chronic illness literature, certain patient characteristics have been shown to interfere with the patient's ability to follow through with health professionals' recommendations, namely depression, comorbid conditions, and substance abuse. For example, in a 2-year prospective study of 1198 patients with chronic medical diseases (hypertension, diabetes, heart disease), Sherbourne et $\mathrm{al}^{19}$ found that patients who were distressed about their health, used avoidant coping strategies, or reported worse physical and role functioning were less likely to adhere in general. Current work ${ }^{20}$ highlights the importance of the physician-patient alliance. Sewitch et $\mathrm{al}^{21}$ found a relationship between physician-patient discordance on health perceptions and adherence in 200 patients with inflammatory bowel disease.

Given that patients with FM fit within the chronic pain and chronic illness categories, we extracted variables from these overlapping literatures to identify candidate variables that could predict adherence in this patient population. We prospectively evaluated general and medication adherence in a cohort of women with FM who were recruited from tertiary care and community settings. We documented the types of services (conventional and complementary) and medications used by our cohort. We used validated instruments to assess general adherence to medical directives and adherence to medications 6 months after an index visit with a rheumatologist, as well as physician-patient discordance. We hypothesized that a combination of clinical (eg, low patient-physician discordance) and psychosocial factors (eg, low psychological distress) would predict (better) adherence in women with FM.

\section{METHODS}

\section{Participants and Procedures}

Eligible participants were women 18 years or older with primary FM who were fluent in English or French.
Ten rheumatologists working in hospitals and private practice settings were asked to invite patients with FM who were scheduled for an office visit to participate in the study. Also, newspaper advertisements were run seeking women with widespread body pain and fatigue. Respondents were screened with a structured telephone interview $^{22}$ to identify those most likely to have FM. Women who screened positive during the telephone interview were examined by a rheumatologist to confirm the FM diagnosis, according to American College of Rheumatology criteria. ${ }^{1}$ Study participants completed a battery of questionnaires on psychosocial (eg, psychological distress, perceived stress, coping strategies), sociodemographic, and clinical (eg, pain, disability, number of comorbid conditions) measures within 72 hours after their visit with the rheumatologist. Both the rheumatologist and patient completed, independently, a validated questionnaire pertaining to the medical visit (results concerning physician-patient discordance are reported elsewhere). ${ }^{23}$ These data constituted the index visit measures. Two weeks later, questions pertaining to medication adherence and health service utilization were posed (the results from this time period are reported elsewhere ${ }^{10,24}$ ). Six months later, participants completed questionnaires on use of health services and adherence to health professionals' recommendations covering the period between the index visit and followup. The research protocol was approved by the McGill University Faculty of Medicine Institutional Review Board as well as all other hospitals not affiliated with McGill University. Written informed consent was obtained.

\section{Measures}

\section{General Adherence}

A measure of general adherence, developed by DiMatteo et $\mathrm{al},{ }^{19}$ that summarized information about the patient's general or typical tendency to adhere to medical recommendations, regardless of the type of recommendation, was administered at 6 months after the index visit. Items include: (1) I had a hard time doing what the doctor suggested I do; (2) I found it easy to do the things my doctor suggested I do; (3) I was unable to do what was necessary to follow my doctor's treatment plans; (4) I followed my doctor's suggestions exactly; and (5) Generally speaking, how often during the past 4 weeks were you able to do what the doctor told you? Response options for each item range from "none of the time" to "all of the time." Responses for items 1 and 3 are reversed and then all responses are summed and averaged. Scale scores are then transformed, resulting in a score of 0 to 100 . The internal consistency of the total score was 0.80 , and the reliability scores at the index visit and follow-up in the original study were 0.78 and 0.79 , respectively, in qpatients with heart disease, hypertension, diabetes, and depression. ${ }^{19}$ 


\section{Medication Adherence}

Adherence to medication was assessed with a fouritem, ordinally scaled validated questionnaire ${ }^{25} 6$ months after the index visit. Adherence to medication in general rather than to specific agents ${ }^{26,27}$ was assessed because the number and types of medications used varied across participants. Responses to the four questions are indicated in binary fashion (yes/no); the time frame was the past 4 weeks. Total scores are obtained by summing the positive responses. In our sample of FM participants, internal consistency was good (Cronbach's $\alpha=0.75$ ). Nonadherence was equal to 1 if patients answered yes to a least one of the four items, and 0 otherwise.

\section{Professionals Consulted; Medications Used}

A modified version of the economic portion of the Stanford Health Assessment Questionnaire (HAQ) was used to collect data on health service utilization. The instrument has been previously used and validated by ourselves and others ${ }^{28-30}$ for systemic lupus erythematosus and other rheumatic diseases. It inquires about the use of all health services during the preceding 6 months without asking the respondent to make attributions to any one disease or condition. Participants reported on outpatient use of physicians, laboratory tests, imaging procedures, emergency rooms, and outpatient surgery as well as on stays in acute care institutions. (These services are covered by universal health care in Canada.) Moreover, they listed medications used, including prescription and nonprescription drugs. (Prescription medications are covered by the Quebec health care system for all citizens who do not have private insurance.)

Complementary/alternative medicine (CAM) was documented in terms of type of health professional consulted, number of visits, and whether the visit was related to FM. The following health professionals were listed: chiropractors, physiotherapists, occupational therapists, podiatrists, ergonomists, psychologists, naturopaths, dietitians, homeopaths, acupuncturists, massage therapists, and osteopaths. (These health professionals are not covered by the Canadian universal health care system.)

\section{Putative Predictors From the Index Visit}

Sociodemographic characteristics included age, language (French or English), family income, martial status, and education.

Social desirability was assessed with a five-item selfreport measure of the extent to which an individual presents him or herself in a socially accepted manner. ${ }^{31}$ Items are rated along a 5-point scale from "definitely true" to "definitely false" and then dichotomized at "definitely true" to reduce incorrect classification of social desirability. Alpha reliability estimates were 0.66 and 0.68 in two outpatient samples $(\mathrm{Ns}=614$ and 3053, respectively); 1 month test-retest reliability was 0.75 in a sample of 75 older adults. ${ }^{31}$ In our sample, internal consistency was adequate (Cronbach's $\alpha=0.59$ ), which in part reflects the small number of items in the scale.

\section{Clinical}

Pain was assessed using the McGill Pain Questionnaire (MPQ) ${ }^{32}$ a self-report measure of a subject's pain experience at the present time. The MPQ contains 78 pain words grouped in 20 subclasses of three to five descriptive words. The 20 subclasses are grouped in four sections (sensory, affective, evaluative, and miscellaneous), which result in four subscores. A Total Pain Rating Score is calculated by summing the pain words selected (maximum 1 per subclass). There is also a global measure of present pain, the Present Pain Index, which is a numeric rating scale that includes a list of adjectives, rank-ordered by level of pain. The MPQ is extensively used and has excellent psychometric properties. ${ }^{33}$

\section{Number of Comorbid Conditions}

Participants were asked to indicate whether they had any other medical conditions. We coded 44 distinct medical conditions. A total score was created by summing the number of conditions endorsed. Scores ranged from 0 (no other condition) to 5 (five or more conditions). Only 14 subjects indicated five or more conditions. In the analyses, this variable was treated as a quantitative variable, assuming linear effects across six values.

\section{Patient-Physician Discordance Scale}

Patient and physician perceptions of health status were assessed independently of each other at the index visit with the Patient-Physician Discordance Scale (PPDS), a questionnaire developed by our team in the context of a study of patients with inflammatory bowel disease $^{34}$ and adapted to FM. ${ }^{23}$ The PPDS is a $100-\mathrm{mm}$ anchored horizontal visual analog scale (VAS) consisting of 10 items derived from the literature on physicianpatient agreement. Items relate to functioning (eg, pain, disease activity, physical limitations, emotional wellbeing, and psychological distress), expectations of the visit (eg, patient desire for further testing and for prescription of medication), communication (eg, discussion of main problem and psychosocial issues), and patient satisfaction with visit.

In patients with inflammatory bowel disease, a principal component factor analysis identified three factors that together explained $51.4 \%$ of total variance: symptoms and treatment (pain, physical limitation, expectations for a prescription and for testing), wellbeing (disease activity, psychological distress, and emotional well-being), and medical encounter (problem discussed, personal issues discussed, and satisfaction with medical visit). Intraclass correlation coefficients calculated on the 10 patient ratings ranged between 0.67 and 0.92 , indicating satisfactory reliability.

For the purpose of this study, two items (expectation for testing and for a prescription) were dropped from the symptoms and treatment subscale as they applied only to participants recruited by rheumatologists in tertiary 
care settings. The modified subscale was renamed "physical functioning" because it consisted of two items: 1 (pain) and 3 (physical limitation). The well-being subscale was retained with no modifications. The medical encounter subscale was not retained because it did not apply to the participants recruited from the community: not all community-based women discussed personal issues with the rheumatologist. A single discordance score on patient satisfaction with the visit was retained as a separate outcome variable. This item asks the physician to consider how satisfied he or she believes the patient felt about the visit; for the other items considered herein, the physician is asked to rate the patient according to his or her perception of the patient's functioning.

\section{Coping}

The Coping with Health Injuries and Problems Scale (CHIP) is a 32-item self-report measure of coping with health problems. ${ }^{35}$ Coping strategies are grouped into four subscales: Instrumental, Palliative, Emotional Preoccupation, and Distraction. Instrumental coping involves task-oriented responses such as seeking health information or advice. For the present study, three items directly pertaining to adherence were removed from the instrumental coping scale to avoid the problem of item overlap between independent and dependent measures. Both the original and modified instrumental coping scales were evaluated in the statistical analyses described below. Palliative coping involves responses to alleviate "unpleasantness," such as resting or making oneself comfortable. Emotional preoccupation coping involves focusing on emotional consequences of the health problem, such as feeling angry or frustrated. Distraction coping involves actions and cognitive processes used to avoid preoccupation with the health problem (eg, thinking about good times, being in the company of others). Participants were instructed to respond to the items using a 5-point scale indicating how often they used these strategies when managing their FM. Scale scores are derived by summing the item responses. Scores for each of the four eight-item subscales range from 8 to 40 . The CHIP has been found to have very good internal consistency, with Cronbach's alphas ranging from 0.70 to 0.78 for distraction, 0.65 to 0.79 for palliative, 0.83 to 0.84 for emotional preoccupation, and 0.73 to 0.83 for instrumental in women 30 to 49 or 50 years or more. ${ }^{36}$ A Cronbach's alpha level of 0.78 was found for the modified instrumental coping scale used in the present study. Good 2-week test-retest reliability scores were reported, with correlations for women being $r=0.82$ for distraction, $r=0.64$ for palliative, $r=0.64$ for instrumental, and $r=0.78$ for emotional preoccupation coping. ${ }^{36}$ Hadjistavropoulos et $\mathrm{al}^{37}$ provided further evidence for the CHIP's factor structure, reliability, and validity in patients with chronic musculoskeletal pain.

\section{Psychological Distress}

Psychological distress was assessed with the Symptom Checklist-90R, a 90-item self-report measure of distress during the past week. ${ }^{38}$ This scale does not yield psychiatric diagnoses. The Global Severity Index (GSI) summary score combines the number and intensity of symptoms and is reported as a normalized $\mathrm{T}$-score (normative mean score $=50, \mathrm{SD}=10$ ). The internal consistency of the GSI in our FM sample was very high, as evidenced by Cronbach's $\alpha=0.97$.

\section{Social Support}

An abbreviated version of the Social Support Questionnaire was used. ${ }^{39}$ The SSQ-6 consists of two subscales assessing the number of people in the network (SSQ-N) and satisfaction with perceived available support (SSQ-S). The scoring for the SSQ-S subscale ranges from 1 to 6 and 0 to 9 for SSQ-N, where higher scores reflect greater satisfaction and a larger network, respectively. Test-retest reliability is high, ${ }^{39}$ and internal consistency in our FM sample was high (Cronbach's $\alpha>0.87)$.

\section{Statistical Analysis}

Descriptive statistics were used to characterize the study population. Social support satisfaction and network size were not normally distributed and were dichotomized at the median values. T-tests and chisquare tests were used to compare tertiary care and community participants on continuous and categorical variables, respectively. To identify the predictors of general adherence and medication adherence, statistical methods for clustered data were used. The generalized estimating equations (GEE) approach ${ }^{40}$ accounts for the possibility that patients within physicians' practices were more alike than patients between practices. It also accounts for the unbalanced structure of the data (ie, for the fact that the number of patients varied across physicians). The GEE analyses were conducted using SAS procedures PROC MIXED for general adherence and PROC GENMOD for medication adherence. The compound symmetry, known as exchangeable structure, of the covariance of errors was assumed a priori and validated against alternative structures using the Akaike's Information Criterion (AIC). ${ }^{41}$ To arrive at the final multivariate models, all independent variables were initially screened for statistical significance $(P<0.05)$ in separate univariate analyses. With the exception of the pain variables that were highly correlated with each other $(P>0.70)$, all variables that were statistically significant in the univariate models were then entered into one multivariate model. Variables retained as predictors of adherence were significant at $P=0.05$.

\section{RESULTS}

\section{Participants}

Of the 182 patients who completed baseline questionnaires, $178(97.8 \%)$ returned the mail-in survey. Of these, $149(81.9 \%)$ provided data on general adherence, $142(95.3 \%)$ on patient-physician discordance, and 121 $(67.9 \%)$ on medication adherence. 
One hundred forty-two subjects were used in the analysis of general adherence. Table 1 presents their demographic, clinical, and psychosocial characteristics. Mean age was 50.9 years $(\mathrm{SD}=10.2)$, and patients reported having FM for a median of 32 months (range $1-276 ;$ mean $=47.06)$. Sixty $(42.3 \%)$ women were

TABLE 1. Description of the Fibromyalgia Cohort $(n=142)$

\begin{tabular}{|c|c|c|}
\hline Characteristic & $\begin{array}{l}\text { n (\%) or Mean } \\
\text { (SD) }\end{array}$ & Range \\
\hline \multicolumn{3}{|l|}{ Demographic } \\
\hline Age (years) & $50.9(10.2)$ & \\
\hline French-speaking & $59(42)$ & $20.6-73.4$ \\
\hline English-speaking & $83(58)$ & \\
\hline \multicolumn{3}{|l|}{ Marital status } \\
\hline Single & $17(12.0)$ & \\
\hline Married & $78(54.9)$ & \\
\hline Separated/divorced & $33(23.2)$ & \\
\hline Widowed & $11(7.7)$ & \\
\hline Education (years) & $13.1(3.3)$ & $3.0-18.0$ \\
\hline \multicolumn{3}{|l|}{ Employment } \\
\hline Working full-time & $42(29.6)$ & \\
\hline Working part-time & $21(14.8)$ & \\
\hline Disabled due to FM & $21(14.8)$ & \\
\hline Retired due to FM & $11(7.7)$ & \\
\hline \multicolumn{3}{|l|}{ Household income } \\
\hline Less than $\$ 20,000$ & $40(28.2)$ & \\
\hline$\$ 20,000-\$ 40,000$ & $32(22.6)$ & \\
\hline$\$ 40,000$ and above & $63(44.4)$ & \\
\hline Missing & $7(4.8)$ & \\
\hline \multicolumn{3}{|l|}{ Clinical } \\
\hline \multicolumn{3}{|l|}{ Time under rheumatologist care } \\
\hline Not applicable & $23(16.2)$ & \\
\hline$\leq 1$ year & $58(40.8)$ & \\
\hline$>1$ year & $61(43.0)$ & \\
\hline $\begin{array}{l}\text { Months of disease duration (median, } \\
\text { IQR) }\end{array}$ & $32(8.8-72)$ & $1-276$ \\
\hline Number of comorbid conditions & $2.1(1.4)$ & $0-5$ \\
\hline \multicolumn{3}{|l|}{ Pain Ratings } \\
\hline Present Pain Intensity & $2.8(1.2)$ & $0-5$ \\
\hline Total Pain Rating & $35.2(15.7)$ & $2-71$ \\
\hline Sensory Pain Rating & $20.8(8.8)$ & $1-40$ \\
\hline Affective Pain Rating & $5.5(3.8)$ & $0-13$ \\
\hline Evaluative Pain Rating & $2.5(1.5)$ & $0-5$ \\
\hline \multicolumn{3}{|l|}{ Psychosocial } \\
\hline $\begin{array}{l}\text { Psychological distress (GSI raw } \\
\text { score)* }\end{array}$ & $1.3(0.7)$ & $0.03-3.39$ \\
\hline $\begin{array}{l}\text { Social support satisfaction (median, } \\
\text { IQR) }\end{array}$ & $5.0(4.0-5.5)$ & $1-6$ \\
\hline $\begin{array}{l}\text { Social support network size (median, } \\
\text { IQR) }\end{array}$ & $2.4(1.5-3.7)$ & $0-9$ \\
\hline $\begin{array}{l}\text { Social desirability (transformed } \\
\text { score) }\end{array}$ & $36.8(28.8)$ & $0-100$ \\
\hline \multicolumn{3}{|l|}{ Coping styles } \\
\hline Distraction Coping & $23.5(6.1)$ & $12-40$ \\
\hline Palliative Coping & $23.7(5.6)$ & $11-39$ \\
\hline Instrumental Coping & $30.0(5.9)$ & $14-40$ \\
\hline Emotional Preoccupation & $24.4(8.3)$ & $8-40$ \\
\hline \multicolumn{3}{|l|}{ Discordance } \\
\hline Well-being & $1.00(0.75)$ & \\
\hline Communication satisfaction & $1.17(1.09)$ & \\
\hline Physical functioning & $0.92(0.77)$ & \\
\hline \multicolumn{3}{|l|}{ Outcome } \\
\hline General Adherence & $61.0(22.4)$ & $0-100$ \\
\hline
\end{tabular}

TABLE 2. Physician Characteristics $(n=10)$

\begin{tabular}{lc}
\hline Characteristic & \% or Median, IQR (range) \\
\hline Age & $43.8,37.3-53.5(30.5-54.2)$ \\
Gender (male) & $70 \%$ \\
Years treating FM patients & $12.5,10.0-20.0(1-21)$ \\
Number of FM patients seen per week & $5.5,3.5-10.0(3-60)$ \\
Position at hospital & \\
Attending staff & $80 \%$ \\
Rheumatologist not on staff & $10 \%$ \\
Resident & $10 \%$ \\
\hline
\end{tabular}

recruited from tertiary care establishments and 82 $(57.7 \%)$ from the community. Compared with tertiary care participants, those from the community engaged in less emotional preoccupation coping (23.2 vs. 26.0, $P=.048)$ and tended to have lower psychological distress (1.18 vs. $1.40, P=0.063)$.

\section{Physicians}

Ten physicians participated in the study (Table 2). Their median age was 43.8 years (interquartile range [IQR] 37.3-57.3). Seven (70\%) were male.

\section{Health Care Provider Use}

Table 3 presents information on health care provider use. On average, patients made $6.2(\mathrm{SD}=5.3)$ visits to physicians and $8.7 \quad(\mathrm{SD}=14.3)$ visits to complementary and alternative health care providers during the 6-month follow-up. Only three patients had not seen a physician during this period. General practitioners were the most consulted physicians, both in terms of frequency of visits and percentage of patients having sought consultation. Massage therapists and physiotherapists were the most frequently consulted complementary/ alternative health care practitioners. Total health care provider use did not differ between the community and tertiary patient groups (data not shown).

TABLE 3. Health Care Provider use by Women With Fibromyalgia $(n=142)$

\begin{tabular}{lc}
\hline Health Care Provider & n (\%) \\
\hline Physician specialty & \\
General practitioner & $118(83.1)$ \\
Rheumatologist & $77(54.2)$ \\
Internist & $16(11.3)$ \\
Gastroenterologist & $9(6.3)$ \\
Psychiatrist & $12(8.5)$ \\
MD other* & $66(46.5)$ \\
Complementary/Alternative Health Care Provider & \\
Psychologist & $18(12.7)$ \\
Physiotherapist & $34(23.9)$ \\
Massage therapist & $39(27.5)$ \\
Acupuncturist & $15(10.6)$ \\
Chiropractor & $14(9.9)$ \\
Occupational therapist & $1(0.7)$ \\
Other $\dagger$ & $33(23.2)$ \\
\hline
\end{tabular}

*Gynecologist, dermatologist, endocrinologist, ophthalmologist, surgeon, pediatrist, otorhinolaryngologist, urologist, lung specialist, cardiologist.

$\dagger$ Naturopath, osteopath, social worker, dietitian, homeopath, occupational therapist, ergonomist. 
TABLE 4. Beta Estimates and $95 \%$ Confidence Intervals for Univariate and Multivariate Generalized Estimating Equations Models for General Adherence $(n=142)$

\begin{tabular}{lcc}
\hline Characteristics & $\begin{array}{c}\text { Univariate Beta } \\
\mathbf{( 9 5 \%} \mathbf{C I})\end{array}$ & $\begin{array}{c}\text { Multivariate Beta } \\
\mathbf{( 9 5 \% ~ C I ) ~}\end{array}$ \\
\hline Social desirability & $0.12(-0.002,0.249)$ & $0.10(-0.02,0.22)$ \\
Present Pain Index & $-4.55(-7.55,-1.55)$ & $-2.95(-6.16,0.25)$ \\
$\begin{array}{l}\text { Well-being } \\
\text { discordance }\end{array}$ & $-5.59(-10.36,-0.82)$ & $-4.58 *(-9.14,-0.03)$ \\
$\begin{array}{l}\text { Psychological } \\
\text { distress }\end{array}$ & $-9.07(-14.30,-3.86)$ & $-6.08 *(-11.74,-0.42)$ \\
\hline & & \\
\hline
\end{tabular}

\section{General Adherence}

The results of the univariate and multivariate GEE models are presented in Table 4 . In the univariate models, higher social desirability, lower psychological distress, lower well-being discordance, and lower Present Pain Index were associated with more general adherence. In the multivariate model, lower psychological distress and lower well-being discordance were statistically significantly associated with more general adherence, whereas social desirability $(P=0.98)$ and Present Pain Index $(P=0.07)$ were marginally significant.

\section{Medication Use}

Of the 121 women with medication adherence data (Table 5), the majority $(69.5 \%)$ listed between 3 and 10 medications used in the previous 6 months, 24 women $(19.8 \%)$ listed at least 11 medications, 4 (3.3\%) participants did not list any medication use, and $2(1.6 \%)$ indicated some form of monotherapy. Antidepressants were the most commonly used medications $(54.5 \%)$. There were no significant differences between tertiary care and community subjects with regard to medication use.

TABLE 5. Medications Used by Women With Fibromyalgia in 6 Months After Index Visit $(n=121)$

\begin{tabular}{lc}
\hline Type of Medication & Overall n (\%) \\
\hline Antidepressant & $66(54.5)$ \\
Anxiolytic & $30(24.8)$ \\
Other psychoactive drugs* & $28(23.1)$ \\
Acetaminophen & $56(46.3)$ \\
NSAIDs & $57(47.1)$ \\
Narcotic analgesics & $50(41.3)$ \\
Hormones & $51(42.1)$ \\
Gastroenterologic & $44(36.4)$ \\
Muscle relaxant & $29(24.0)$ \\
Vitamins & $48(39.7)$ \\
Alternative & $19(15.7)$ \\
Other $\dagger$ & $79(65.3)$ \\
\hline
\end{tabular}

*Includes anticonvulsant medications used to treat chronic pain (eg, gabapentin).

$†$ Vitamins, alternative medications, and other not listed medications.
TABLE 6. Responses to Questions on Medication Adherence in Women With Fibromyalgia

\begin{tabular}{lc}
\hline Nonadherence to Medication & Overall $\mathbf{n}=\mathbf{1 2 1}(\mathbf{\%})$ \\
\hline $\begin{array}{l}\text { Did you forget to take your medication? } \\
\text { Were you careless at times about taking your } \\
\text { medication? }\end{array}$ & $42(34.7)$ \\
$\begin{array}{l}\text { When you felt better, did you sometimes stop } \\
\text { taking your medication? }\end{array}$ & $33(21.5)$ \\
$\begin{array}{l}\text { If you felt worse when you took your } \\
\text { medication, did you sometimes stop taking }\end{array}$ & $31(25.6)$ \\
$\quad \begin{array}{l}\text { your medication? } \\
\text { Endorsement of at least one item }\end{array}$ & $64(52.9)$ \\
\hline
\end{tabular}

\section{Medication Adherence}

Table 6 presents the responses to the medication adherence questionnaire. More than half (52.9\%) of the sample reported at least one form of nonadherent behavior. Community and tertiary care participants did not differ with respect to nonadherence to medication (data not shown).

The results of the univariate and multivariate GEE models are shown in Table 7 . In the univariate models, higher sensory and affective pain ratings, higher satisfaction with social support, higher instrumental coping (original scale), and lower psychological distress were associated with increased medication adherence. However, instrumental coping was no longer statistically significant after removal of the three items pertaining to adherence. In the multivariate model, higher affective pain ratings and lower psychological distress were statistically significantly associated with increased likelihood of medication adherence, whereas social support satisfaction $(P=0.08)$ was marginally significant.

\section{DISCUSSION}

This is the second study addressing medication adherence and the first to prospectively examine general adherence in women with FM. As previously reported, ${ }^{24}$ the women in this study sought services from multiple doctors and CAM providers and used many medications. Although it was not possible to link adherence to a particular health professional's advice or to a

TABLE 7. Odds Ratios (OR) and $95 \%$ Confidence Intervals (Cl) for Univariate and Multivariate Generalized Estimating Equations Models for Adherence to Medication $(n=121)$

\begin{tabular}{lcc}
\hline Determinants & $\begin{array}{c}\text { Univariate OR } \\
\mathbf{( 9 5 \%} \mathbf{C I})\end{array}$ & $\begin{array}{c}\text { Multivariate OR } \\
(\mathbf{9 5 \%} \text { CI) }\end{array}$ \\
\hline Sensory pain & $1.02(1.00,1.05)$ & NA \\
Affective pain & $1.05(1.00,1.11)$ & $1.09 *(1.02,1.18)$ \\
Social support satisfaction & $2.17(1.18,3.99)$ & $1.80(0.93,3.48)$ \\
Psychological distress & $0.65(0.50,0.84)$ & $0.57 *(0.35,0.92)$ \\
\hline
\end{tabular}

OR $>1$ indicates increased likelihood of adherence. $O R<1$ indicates decreased likelihood of adherence.

$* P<0.05$. 
specific medication, we identified factors that influenced adherence.

The predictors of higher general adherence to health professionals' recommendations were low patient psychological distress and low patient-physician discordance on patient well-being. The latter variable consisted of three items on the PPDS: psychological distress, disease activity, and emotional well-being. It is plausible that a discrepancy in patient-physician ratings of patients' well-being could result in physicians prescribing treatments that are inconsistent with patients' views of their illness and their expectations. This, in turn, could increase the likelihood that patients would not follow physicians' recommendations. For example, we noted elsewhere $^{23}$ that the examining rheumatologists rated patients' emotional well-being significantly lower than did patients at the index visit. If physicians attribute patients' suffering to emotional factors and patients attribute their own suffering to physical factors, it is logical that, in general, patients tend not to heed physicians' advice. However, the examining rheumatologist was not always the physician dispensing the medical directives. Thus, the importance of this variable rests on the encounter being a typical sampling of patient behavior-that is, it represents what occurs in other medical encounters. This implies that the patient brings to the office visit a stable behavioral style that may influence (negatively or positively) the therapeutic relationship.

The relationship found between high psychological distress and less adherence is consistent with much of the literature for chronically ill patients ${ }^{42}$ (for an exception see ${ }^{19}$ ). Perhaps distress compromises cognitive functioning such that patients fail to recall instructions from health professionals. Distress may overshadow hope and thereby reduce motivation to carry out behaviors (eg, exercise) or make lifestyle changes (eg, pace activities). Equally as plausible, distress may hinder interpersonal relationships, including those with health professionals, blocking fruitful exchanges that may influence subsequent behaviors. Given that psychological distress is common in individuals with FM and higher in individuals seeking treatment in tertiary care, ${ }^{43}$ adherence in this group would be more difficult to achieve. Thus, clinicians may wish to address both distress and adherence head on with patients with the greatest symptoms.

In another report stemming from this cohort at 2 weeks after the index visit, nonadherence to medications was predicted by higher patient-physician discordance on communication and satisfaction. ${ }^{10}$ Six months later, we found that higher affective pain predicted increased likelihood of medication adherence, whereas more psychological distress predicted decreased likelihood of medication adherence. At this later point in time, patient-physician discordance did not enter the model. Perhaps this was due to the distal nature of that encounter. Similar to other chronic pain patients, women with FM who had more pain may have relied more on medications to control pain. Consistent with our findings for general adherence, lower psychological distress predicted adherence to medications. Other variables found to be associated with adherence in the chronic pain and illness literatures (eg, social support) did not prove to be independent predictors for this cohort.

It could be argued that the women examined for study purposes only (ie, the community participants) were not "patients" and the office visit was not a "real" medical encounter. However, these types of office visits are common, as rheumatologists often see FM patients in the context of a consultation visit, on a one-time-only basis. In this study, one third of tertiary care patients were first-time consults and therefore similar to community women in that the purpose of the visit was to confirm the diagnosis of FM. In addition, because most tertiary care patients were not regularly followed by the examining rheumatologist and $80 \%$ of the community participants had previously consulted a rheumatologist, the distinctions between the two groups are likely unimportant. The fact that about half of the sample was derived from the community may enhance external validity because not all individuals with FM seek services in tertiary care settings.

No method of assessing adherence to medication is infallible. We selected a self-report measure because selfreported adherence to medications correlates well with pill counts, ${ }^{44}$ electronic monitoring, and pharmacy refill records, ${ }^{27}$ and because less practical methods of assessment may not overcome concealment. ${ }^{45}$ Moreover, social desirability, which was found to be similar to levels previously reported in medical and mental health outpatients, ${ }^{31}$ was included in the general and medication adherence models to examine the issue of positive selfreport bias. Given that biologic assays are inappropriate in FM because there is no known serologic marker of disease activity, one must rely on self-report measures of adherence in this population.

What are the clinical implications of these findings? Over a decade ago, Turk and Rudy ${ }^{13}$ noted that "compliance + alliance = adherence"; they underscored the importance of involving the patient in the design and mode of implementing the treatment regimen. Data from our current and previous studies point to the importance of the patient-physician relationship for general adherence in the long term and medication adherence in the short term. The patient-physician relationship can be enhanced by improving physicians' knowledge of FM and educating patients about how to effectively communicate their needs and concerns to their physicians. On the other hand, the patient-physician relationship may be undermined by the lack of follow-up visits (eg, rheumatologists confirm the diagnosis but do not treat the patient thereafter). ${ }^{46}$ Thus, continuity of care is likely to improve patient-physician rapport and adherence. Equally important is the need to address FM patients' psychological distress as it hampers adherence. This would need to be done with tact, as physicians considered the patients as more distressed than the patients viewed themselves, and patients are hypersensitive to the "it's all in your head" message that may 
inadvertently be communicated when the physician focuses on the mental health aspect of FM.

This work constitutes an exploration of adherence in FM. Future studies need to address adherence to specific treatment components of multidisciplinary treatment (cognitive-behavioral therapy, physiotherapy, medication), as it may differ across behaviors. Also, adherence needs to be assessed during and after a treatment program, as it may vary over time. Importantly, adherence needs to be directly linked to outcomes of treatment. It is likely that there is a feedback loop: those who perceive benefits from a particular intervention are more likely to continue to carry out the behavior.

\section{ACKNOWLEDGMENTS}

The following physicians examined patients: Drs. Martin Cohen, Mary-Ann Fitzcharles, Michael Starr, Jan Schulz, Murray Baron, Pierre Dagenais, Suzanne Mercille, Anne St-Pierre, Sasha Bernatsky, and Harbhajan Kang. Ms. Tammy Allan provided excellent secretarial support. The authors thank the women with FM who participated in the study, Dr. Mirella De Civita for her critical review of the manuscript, and Ms. Natalie Dayan for recruitment and data management throughout the study.

\section{REFERENCES}

1. Wolfe F, Smythe HA, Yunus MB. The American College of Rheumatology 1990 criteria for the classification of fibromyalgia: report of the multicenter criteria committee. Arthritis Rheum. 1990;33:160-172.

2. Melzack R. Pain and stress: a new perspective. In: Gatchel RJ, Turk DC, eds. Psychosocial Factors in Pain. New York: Raven Press; 1999:89-106.

3. Bennett RM. Fibromyalgia. In: Giamberardino MA, ed. An Updated Review: Refresher Couse. Seattle: IASP Press; 2002:37-49.

4. Gran JT. The epidemiology of chronic generalized musculoskeletal pain. Best Practice \& Research Clin Rheumatol. 2003;17:547-561.

5. Robinson RL, Birnbaum HG, Morley MA, et al. Economic cost and epidemiology characteristics of patients with fibromyalgia claims. J Rheumatol. 2003;30:1318-1325.

6. Turk DC, Okijuji EA, Sinclair JD, et al. Interdisciplinary treatment for fibromyalgia syndrome: clinical and statistical significance. Arthritis Care Res. 1998;11:186-195.

7. Vlaeyen J, Teeken-Gruben N, Goossens M, et al. Cognitiveeducational treatment of fibromyalgia: a randomized clinical trial. I. Clinical effects. J Rheumatol. 1996;23:1237-1245.

8. Bennett RM. Multidisciplinary group programs to treat fibromyalgia patients. Rheum Dis Clin North Am. 1996;22:351-367.

9. Huyser B, Buckelew SP, Hewett JE, et al. Factors affecting adherence to rehabilitation interventions for individuals with fibromyalgia. Rehabil Psychol. 1997;42:75-91.

10. Sewitch MJ, Dobkin PL, Bernatsky S, et al. Medication nonadherence in women with fibromyalgia. Rheumatology. 2004:43:648-654.

11. Buchwald D. Controversies in fibromyalgia and related conditions. Rheum Dis Clin North Am. 1996;22:219-243.

12. Noble LM. Doctor-patient communication and adherence to treatment. In: Myers LB, Midence K, eds. Adherence to Treatment in Medical Conditions. London, UK: Harwood Academic Publishers; 1998:51-82.

13. Turk DC, Rudy TE. Neglected topics in the treatment of chronic pain patients: relapse, noncompliance, and adherence enhancement. Pain. 1991;44:5-28.

14. Carosella AM, Lackner JM, Feuerstein M. Factors associated with early discharge from a multidisciplinary work rehabilita- tion program for chronic low back pain. Pain. 1994;57: 69-76.

15. Feuerstein M, Theberge RW. Perceptions of disability and occupational stress as discriminators of work disability in patients with chronic pain. J Occup Med. 1991;1:185-195.

16. Barnes D, Smith D, Gatchel RJ, et al. Psychosocioeconomic predictors of treatment success/failure in chronic low back pain patients. Spine. 1989;14:427-430.

17. Hazard RG, Bendix A, Fenwick JW. Disability exaggeration as a predictor of functional restoration outcomes for patients with chronic low back pain. Spine. 1991;14:1062-1067.

18. Davis M, Addis ME. Predictors of attrition from behavioral medicine treatments. Ann Behav Med. 1999;21:339-349.

19. Sherbourne CD, Hays RD, Ordway L, et al. Antecedents of adherence to medical recommendations: results from the Medical Outcomes Study. J Behav Med. 1992;15:447-468.

20. Golin CE, DiMatteo MR, Gelberg L. The role of patient participation in the doctor visit: implications for adherence to diabetes care. Diabetes Care. 1996;19:1153-1164.

21. Sewitch MJ, Dobkin PL, Abrahamowicz M. Effect of discordant physician-patient perceptions on medication adherence in inflammatory bowel disease. Am J Epidemiol. 2001;153:S219.

22. White KP, Harth M, Speechley M, et al. Testing an instrument of screen for fibromyalgia syndrome in general population studies: the London Fibromyalgia Epidemiology Study Screening Questionnaire. $J$ Rheumatol. 1999;26:880-884.

23. Dobkin PL, De Civita M, Abrahamowicz M, et al. Patientphysician discordance in fibromyalgia. $J$ Rheumatol. 2003;30: $1326-1334$.

24. Penrod JR, Bernatsky S, Adam V, et al. Health service costs and their determinants in women with fibromyalgia. $J$ Rheumatol. 2004;31.

25. Morisky DE, Green LW, Levine DM. Concurrent and predictive validity of a self-reported measure of medication adherence. Med Care. 1986;24:67-74.

26. Kravitz RL, Hays RD, Sherbourne CD, et al. Recall of recommendations and adherence to advice among patients with chronic medical conditions. Arch Intern Med. 1993;153:1869-1878.

27. Choo PW, Rand CS, Inui TS, et al. Validation of patient reports, automated pharmacy records and pill counts with electronic monitoring of adherence to antihypertensive therapy. Med Care. 1999;37:846-857.

28. Clarke AE, Esdaile JM, Bloch DA, et al. A Canadian study of the total medical costs for patients with systemic lupus erythematosus and the predictors of costs. Arthritis Rheum. 1993;36: $1548-1559$

29. Clarke AE, Petri MA, Manzi S, et al. An international perspective on the well-being and health care costs for patients with systemic lupus erythematosus. J Rheumatol. 1999;26:1500-1511.

30. Clarke AE, Zowall H, Levinton C, et al. Direct and indirect medical costs incurred by Canadian patients with rheumatoid arthritis: a 12-year study. J Rheumatol. 1997;24:1051-1060.

31. Hays RD, Hayashi T, Stewart AL. A five-item measure of socially desirable response set. Educ Psychol Meas. 1989;49:629-636.

32. Melzack R. The McGill Pain Questionnaire: major properties and scoring methods. Pain. 1975;1:277-299.

33. Reading AE. The McGill Pain Questionnaire: an appraisal. In: Melzack R, ed. Pain Measurement and Assessment. New York: Raven Press; 1983:55-61.

34. Sewitch MJ, Abrahamowicz M, Dobkin PL, et al. Measuring differences between patients' and physicians' perceptions: the Patient-Physician Discordance Scale. J Behav Med. 2003;26: 245-264.

35. Endler NS, Parker JDA, Summerfeldt LJ. Coping with health problems: developing a reliable and valid multidimensional measure. Psychol Assoc. 1998;10:195-205.

36. Endler NS, Parker JDA. Coping with Health Injuries and Problems (CHIP). Ontario: Multi-Health Systems Inc.; 2000.

37. Hadjistavropoulos HD, Asmundson JG, Norton GR. Validation of the Coping with Health, Injuries, and Problems scale in a chronic pain sample. Clin J Pain. 1999;15:41-49. 
38. Derogatis LR. SCL-90-R: Administration, Scoring and Procedures Manual. Minneapolis: National Computer System; 1994.

39. Sarason IG, Levine HM, Basham RB, et al. Assessing social support: the Social Support Questionnaire. J Pers Soc Psychol. 1983;44:127-139.

40. Liang KY, Zeger SL. Longitudinal data analysis using generalized linear models. Biometrika. 1986;73:13-22.

41. Jenrich R, Schluchter M. Unbalanced repeated-measures models with structured covariance matrices. Biometrics. 1986;42: 805-820.

42. Dunbar J. Predictors of patient adherence: patient characteristics. In: Shumaker SA, Schron EB, Ockene JK, et al, eds. The Handbook of Health Behavior Change. New York, NY: Springer Pub Co.; 1990:348-360.

43. Kersh BC, Bradley LA, Alarcon GS, et al. Psychosocial and health status variables independently predict health care seeking in fibromyalgia. Arthritis Rheum. 2001;45:362-371.

44. Haynes RB, Taylor DW, Sackett D, et al. Can simple clinical measurements detect patient noncompliance? Hypertension. 1980;2:757-764.

45. DiMatteo MR, Hays RD. Adherence to cancer regimens: implications for treating the older patient. Oncology. 1992;6:50-57.

46. Becker MH, Maimon LA. Strategies for enhancing patient compliance. J Community Health. 1980;6:113-135. 